\title{
Expression pattern of meiosis associated $S Y C P$ family members during germline development in chickens
}

\author{
Ying Hui Zheng, Deivendran Rengaraj, Jin Won Choi, Kyung Je Park, Sang In Lee and Jae Yong Han \\ WCU Biomodulation Major, Department of Agricultural Biotechnology and Research Institute for Agriculture and Life \\ Sciences, Seoul National University, Seoul 151 921, South Korea \\ Correspondence should be addressed to J Y Han; Email: jaehan@snu.ac.kr
}

\begin{abstract}
Synaptonemal complexes (SCs) are associated with synapsis of homologous chromosomes, chiasmata distribution, recombination and segregation of chromosomes during the extended prophase of meiosis I. Three isoforms of SC proteins, SYCP1, SYCP2 and SYCP3, were identified as the structural proteins of SCs, and may be involved in the assembly and disassembly of SCs. The aim of this present study is to determine the pattern of expression of chicken homologues of SYCP family members during ovarian and testicular development. Protein sequence analysis using CLUSTAL $X$ revealed that the sequences and potential phosphorylation sites of chicken SYCP family proteins were highly conserved with mammalian homologues of SYCP family proteins. Quantitative real-time-PCR and in situ hybridisation analysis revealed that chicken $S Y C P$ family members were differentially expressed during ovarian and testicular development. During ovarian development, all chicken SYCP family members were detected in primordial germ cells (PGCs) until embryonic day (E) 8.0; the expression continued in proliferating pre-meiotic oogonia until E15.5 and was upregulated in meiotic prophase I oocytes until hatching. After hatching, all chicken SYCP family members were detected at a low level until 24-weeks-old. During testicular development, all chicken SYCP family members were detected in PGCs until E13.0; the expression continued in pro-spermatogonia and proliferating spermatogonia for up to 8 weeks, and was upregulated in meiotic prophase I spermatocytes in adults. Our data demonstrate the expression pattern of meiosis associated SYCP family members during ovarian and testicular development in chickens.

Reproduction (2009) 138 483-492
\end{abstract}

\section{Introduction}

Gametogenesis occurs immediately after the transition of diploid cells to the haploid state in two successive nuclear divisions, meiosis I and II. Meiosis I has an extended prophase which includes five sequential stages: leptotene; zygotene; pachytene; diplotene; and diakinesis. Synapsis of homologous chromosomes, chiasmata distribution, recombination and segregation of chromosomes at the extended prophase of meiosis I are associated with synaptonemal complexes (SCs; Meuwissen et al. 1992). SCs are meiosis-specific proteinaceous structures that are formed between homologous chromosomes at the pachytene stage of meiotic prophase I. SCs consist of two proteinaceous axes, the lateral elements (LEs), one along each homologue. LEs are connected along their length by numerous transverse filaments (TFs). A third longitudinal structure, the central element, is located on the TFs between both LEs of SCs (Lammers et al. 1994, Meuwissen et al. 1997). Three isoforms of SC proteins (SYCPs), SYCP1, SYCP2 and SYCP3 (also known as SCP1, SCP2 and SCP3), have been identified in mammals as structural component proteins in SCs
(Meuwissen et al. 1992, Lammers et al. 1994, Offenberg et al. 1998). SYCP1 is the major component of the TFs of SCs, whereas SYCP2 and SYCP3 have been identified in the LEs (Ollinger et al. 2005). Mutations of SYCP family members accelerate meiosis I arrest, and mutants display severe alterations in early meiotic cells during gametogenesis (Costa et al. 2005). In SYCP1 mutants, LEs are formed and homologous chromosomes align, but do not undergo synapsis; however, SYCP2 and SYCP3 mutants exhibit failure in the formation of LEs (Yang et al. 2006).

Although several genes/proteins are involved in SC functions, SYCP family members stand out as the most important components. Little is known about SYCP family members in non-mammalian species. In the present study, we focused on investigation of the chicken homologues of $S Y C P$ family members (cSYCP1, cSYCP2 and $c S Y C P 3$ ). We examined the structural similarities of predicted CSYCP family proteins with known SYCP family proteins in humans (hSYCP1, hSYCP2 and hSYCP3), mice (mSYCP1, mSYCP2 and mSYCP3) and rats (rSYCP1, rSYCP2 and rSYCP3) using the CLUSTAL X programme. The expression pattern of CSYCP family members at different stages of ovarian and testicular development was examined using quantitative 
real-time-PCR (qRT-PCR). Furthermore, we examined the mRNA localisation of one candidate gene, cSYCP3, and a germline-specific gene, chicken vasa homologue $(\mathrm{CVH})$, during ovarian and testicular development using in situ hybridisation. All cSYCP family members were differentially expressed during ovarian and testicular development. Our data demonstrate the expression pattern of meiosis associated SYCP family members during ovarian and testicular development in chickens.

\section{Results}

\section{Multiple sequence alignment of SYCP family members}

Predicted gene sequences of $\mathrm{CSYCP}$ family members were obtained from a UCSC BLAT search and NCBI GenBank sequences from the chicken genome. cSYCP1 was mapped to chromosome 26 in chicken genome database. The mRNA sequence of $\mathrm{c} S Y C P 1$ contains an open reading frame of 1446 bp encoding a 481 -amino acid protein. The structure of CSYCP1 protein consists of eight S/T-S/T motifs. S/T-S/T motifs are similar to S/T-P motifs that are common in many different DNA-binding proteins (Suzuki 1989). Other important features present in CSYCP1 include two nuclear localisation signals (K-R/K-X-R/K, where $\mathrm{X}$ represents any amino acid; Roberts 1989), one cAMP/cGMP-dependent protein kinase binding motif (RR/KK-X-S/T; Glass et al. 1986), four potential phosphorylation sites for protein kinase $C$ (PKC; S/T-X-R/K; Kishimoto et al. 1985) and four potential phosphorylation sites for casein kinase II (S/T-X-X-D/E; Pinna 1990). Of these, two DNA-binding sites and two potential phosphorylation sites, one each for PKC and casein kinase II, are conserved in hSYCP1 (Fig. 1).

CSYCP2 was mapped to chromosome 20 in chicken genome database. The mRNA sequence of cSYCP2 contains an open reading frame of 2478 bp encoding an

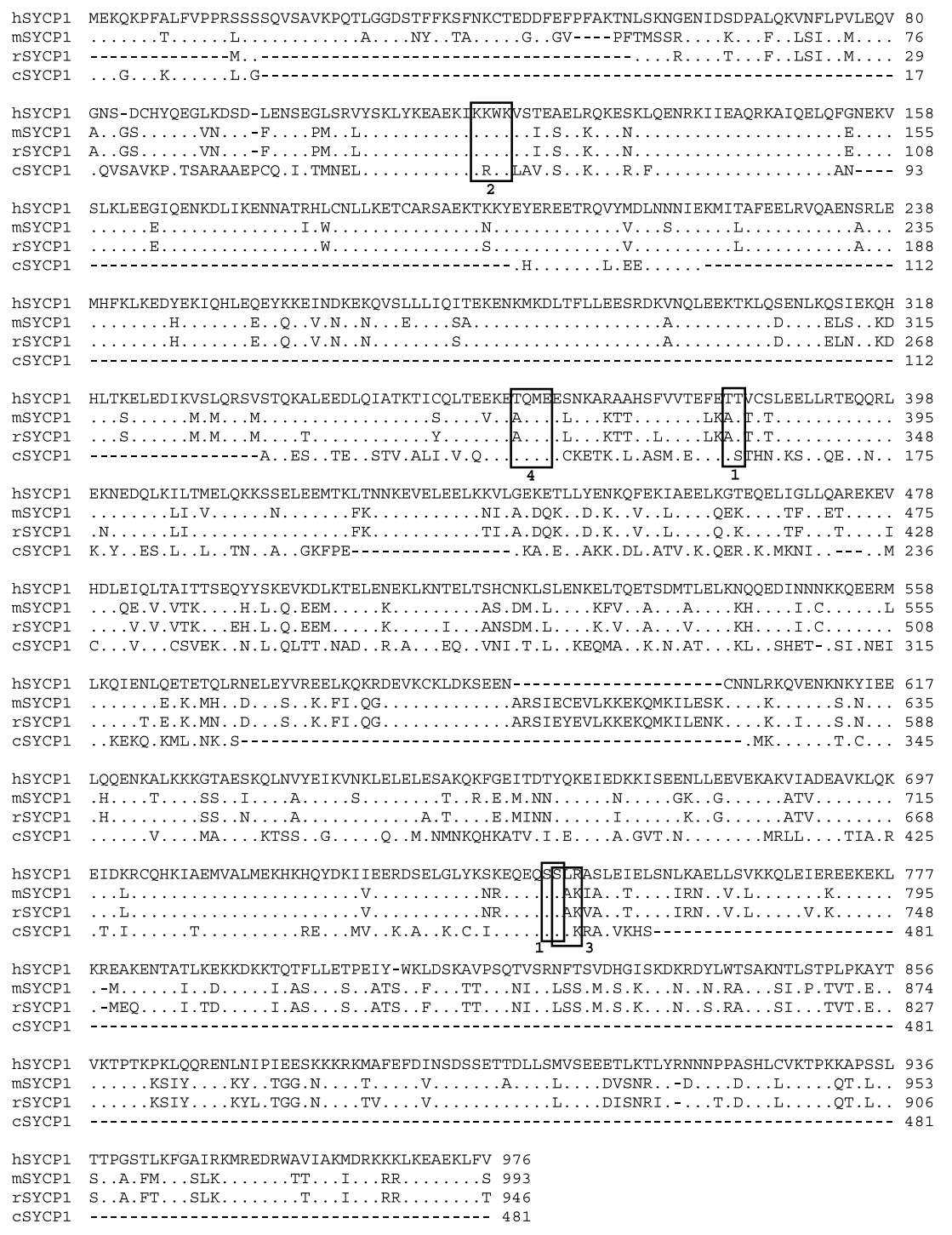

Figure 1 Amino acid sequence alignment of synaptonemal complex protein 1 (SYCP1) proteins. Amino acid sequences of known SYCP1 proteins from humans (hSYCP1), mice (mSYCP1) and rats ( $\mathrm{rSYCP} 1)$ were compared with the predicted SYCP1 protein from chickens (CSYCP1) using the CLUSTAL X programme and edited with the BioEdit programme. Dots indicate amino acids identical to hSYCP1 and dashes represent gaps in the sequence. Amino acid sequences shown in boxes are the following: 1) DNAbinding sites (S/T-S/T motifs), 2) nuclear localisation signal $(K-R / K-X-R / K$, where $X$ represents any amino acid), 3) protein kinase $C$ phosphorylation site (S/T-X-R/K), and 4) casein kinase II phosphorylation site (S/T-X-X-D/E), which are conserved in both hSYCP1 and CSYCP1. 
825-amino acid protein. The structure of CSYCP2 contains more features than that of other members of the cSYCP family, including $13 \mathrm{~S} / \mathrm{T}-\mathrm{P}$ motifs, $30 \mathrm{~S} / \mathrm{T}-\mathrm{S} / \mathrm{T}$ motifs, 4 nuclear localisation signals, 1 potential phosphorylation site for tyrosine kinase (R/K-X-X-D/E$\mathrm{X}-\mathrm{X}-\mathrm{X}-\mathrm{Y}$; Cooper et al. 1984), 6 potential phosphorylation sites for cAMP/cGMP-dependent protein kinase, 24 potential phosphorylation sites for PKC, 23 potential phosphorylation sites for casein kinase II and 1 GTP-binding site (D-X-X-G; Dever et al. 1987). Of these, 16 DNA-binding sites, 3 phosphorylation sites for PKC, 5 phosphorylation sites for casein kinase II and 1 GTP-binding site are conserved in hSYCP2 (Fig. 2).

cSYCP3 was mapped to chromosome 1 in chicken genome database. The mRNA sequence of cSYCP3 consists of an open reading frame of 717 bp encoding a 238-amino acid protein. The cSYCP3 protein is short compared to CSYCP1 and CSYCP2, but is highly homologous with mammalian SYCP3 proteins. The structure of CSYCP3 contains one S/T-P motif, two S/T-S/T motifs, one nuclear localisation signal, six potential phosphorylation sites for PKC, five potential phosphorylation sites for casein kinase II and four GTP-binding sites. Of these, two DNA-binding sites, the nuclear localisation signal, six phosphorylation sites for PKC, four phosphorylation sites for casein kinase II and two GTP-binding sites are conserved in hSYCP3 (Fig. 3).

Calculating the percentage identity of CSYCP family proteins with mammalian SYCP family proteins over the entire alignment indicated significant similarities: the protein sequence identity between CSYCP1 and SYCP1 in humans, mice and rats was 45, 44 and 44\% respectively; between CSYCP2 and SYCP2 in humans, mice and rats was 38, 39 and $39 \%$ respectively; and between CSYCP3 and SYCP3 in humans, mice and rats was 75, 68 and $70 \%$ respectively. In addition, CSYCP1 and CSYCP2 lack nearly half of the amino acid sequence of mammalian SYCP1 and SYCP2 respectively.

\section{Tissue specificity and duration of expression of CSYCP family members}

The expression levels of cSYCP1, cSYCP2 and cSYCP3 were examined by qRT-PCR during ovarian and testicular development on embryonic day (E) E6.0, E8.0, E12.0, 1 day (hatching), 5, 8, 10, 12 and 24 weeks. The cSYCP family members were differentially expressed during ovarian and testicular development. In the female gonad, all three members of the cSYCP family were initially expressed on E6.0 at a low level, and the expression was developmentally upregulated until hatching. After hatching, the expression of cSYCP1 and $\mathrm{CSYCP} 3$ was detected at a low level until 24 weeks. The relative expression level of ${ }^{C S Y C P 2}$ was low compared to the other two members of the cSYCP family. After hatching, cSYCP2 was expressed at a low level in ovaries and maintained the same level until 24 weeks (Fig. 4).

In males, expression of cSYCP1 first appeared at a low level in E6.0 gonads, and the same level was maintained until hatching. After hatching, cSYCP1 was developmentally upregulated until 24 weeks. Similar to cSYCP1, cSYCP2 first appeared at a low level in gonads on E6.0, but the level was maintained until 8 weeks. cSYCP2 expression increased after 10 weeks and reached a maximum at 24 weeks. cSYCP3 differed from the other SYCP family members because it was initially expressed in gonads on E8.0. cSYCP3 expression increased at every age examined and reached its highest level of expression at 24 weeks (Fig. 4).

Because the relative expression level of cSYCP family members was high at 24 weeks, particularly in testis, we further examined one candidate gene, cSYCP3, in adult tissues by northern blotting. The expression of cSYCP3 mRNA was detected in adult testis. No cSYCP3 mRNA was detected in the brain, liver, muscle, spleen or ovary at 24 weeks (Fig. 5).

\section{mRNA localisation of CSYCP3 during ovarian and testicular development}

We used in situ hybridisation to examine mRNA localisation of one candidate gene, $\mathrm{CSYCP} 3$, during ovarian development on E8.0, E12.0, 1 day and 5 weeks, and testicular development on E8.0, E12.0, 1 day, 5 and 24 weeks. CSYCP3 is expressed differentially during ovarian and testicular development in chickens. In females, cSYCP3 mRNA was detected in primordial germ cells (PGCs), pre-meiotic germ cells and meiotic prophase I oocytes. On E8.0, the cSYCP3 signal was detected in PGCs, which migrated to the peripheral region of the gonads; consistent with this observation, fewer cSYCP3-positive PGCs were detected in the medullary region of gonads. Starting on E12.0, the cSYCP3 signal increased, particularly in pre-meiotic germ cells and meiotic prophase I oocytes located in the cortex area. cSYCP3-positive meiotic prophase I oocytes were widespread in ovaries on day 1 (Fig. 6). cSYCP3 mRNA was detected at a low level in ovaries at 5 weeks (data not shown).

In males, cSYCP3 mRNA expression was developmentally upregulated from E8.0 to 24 weeks of age. On E8.0 and E12.0, cSYCP3 mRNA was detected in PGCs that had migrated to the differentiating seminiferous cords. After that, cSYCP3 mRNA expression continued in the pro-spermatogonia (until hatching) and proliferating spermatogonia (on 1 day to 8 weeks). At 24 weeks, cSYCP3 mRNA was strongly detected in meiotic prophase I spermatocytes (Fig. 7). The expression pattern of $\mathrm{CSYCP} 3$ during ovarian and testicular development in chicken embryos resembles that of the germline-specific gene, $\mathrm{CVH}$ (Figs 6 and 7). 


\begin{tabular}{|c|c|c|}
\hline & LRKNDFKPLKTLLQIDICEDVKIKCSKQFFHKVDNLICRELNKEDIHNVSAIL & 30 \\
\hline mSYCP2 & ..K..QT..S.I.I...S. & 80 \\
\hline rSYCP2 2 & .H.K. .QTI.N. .I.I...S. & 80 \\
\hline CSYCP2 & & 1 \\
\hline YCP2 & LVIHD & 160 \\
\hline mSYCP2 2 & .S...N. .E. LN.QQ. & 160 \\
\hline rSYCP2 & 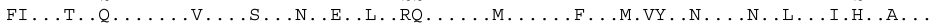 & 160 \\
\hline P2 & & \\
\hline
\end{tabular}

hSYCP2 DSRVNICIQQEI IKKMNAMLDKMPQDARKILSNQEMLILMSSMGERILDAGDYDLQVGIVEALCRMTTEKQRQELAHQWF 240

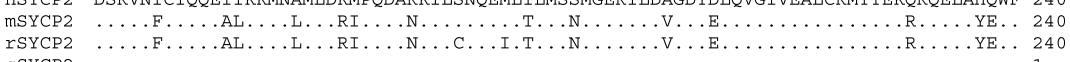
hSYCP2 SMDFIAKAFKRIKDSEFETDCRIFLNLVNGMLGDKRRVFTFPCLSAFLDKYELQIPSDEKLEEFWIDFNLGSQTLSFYIA 320 MSYCP2
MSYCP2 $\ldots \ldots$ N IAKAFRIKDSEFETDCRIFLNLVNGMLGDKRRVFTFPCLSAFLDKYELQIPSDEKLEEFWIDFNLGSQTLSFYIA 320

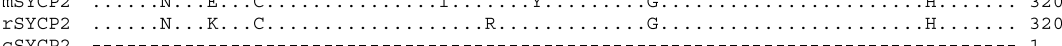

hSYCP2 GDNDDHQWEAVTVPEEKVQIYSIEVRESKKLLTIILKNTVKISKREGKELLLYFDASLEITNVTQKIFGATKHRESIRKQ 400

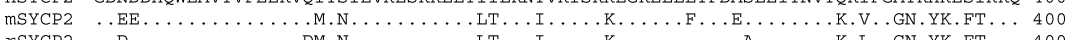

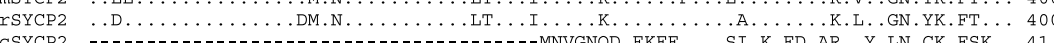

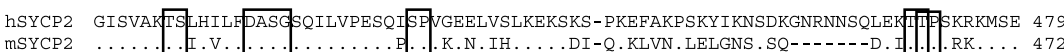

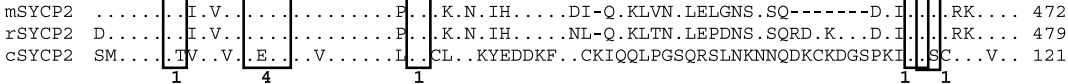
hSYCP2 ASMIVSGADRYTMR PPVLFSNTAIPPRRRRIKPPLQMI SSAEKPSVSQTSENRVDNAASLKSRSSEGRHRRDNIDKHIKT 559

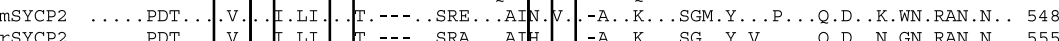

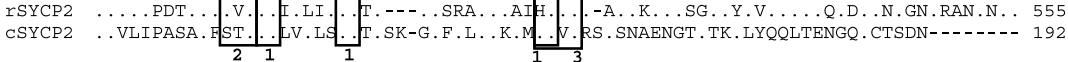
hSYCP2 AKCVENTENKNVEFPNQNFSELQDVIPDSQ-AAEKRDHTILPGVLDNICGNKIHSKWACWTPVTNIELCNNQRASTSSGD 638 mSYCP2 TAVIQ.KQYEDN.S.D...N.IE.TLSNVSS.VG.V.KPV.......SK.TT..R..............SRALP.. 627

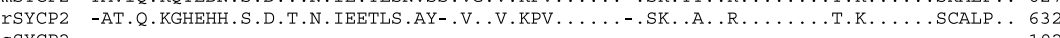
CSYCP2

hSYCP2 TLNQDIVINKKLTKQKSSSSISDHNSEGTGKVKYKKEQTDHIKIDKAEVEVCKKHNQQQNHPKYSGGQKNTENAKQSDWPV 718

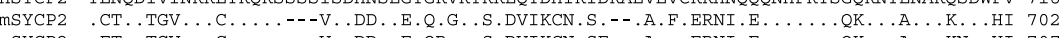

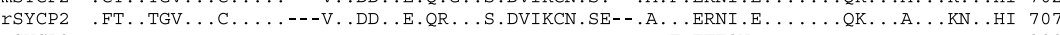
CSYCP2

hSYCP2 ESETTFKSVLLNKTIEESLIYRKKYILSKDVNTATCDKNPSASKNVQSHRKAEKELTSELNSWDSKQKKMREKSKGKEFT 798

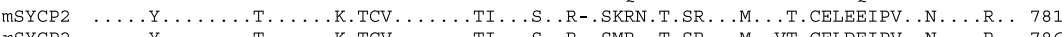

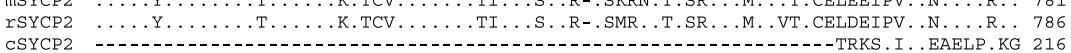

hSYCP2 NVAESLISQINKRYKTKDDIK K TRKLKESLINSGFSNKPVVQLSKEKVQKKSYRKLKTTFVNVTSECPVNDVYNFNLNGA 878

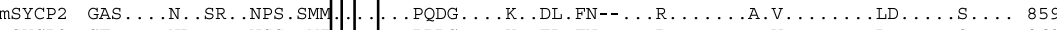

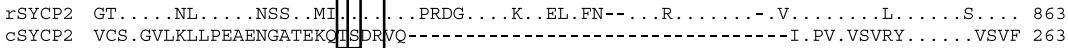
$\begin{array}{cc}1 & 2 \\ \text { hSYCP2 DDPIIKLGIQEFQATAKEACADRSIRLVGPRNHDELKSSVKTKDKKIITNHQKKNLFFPFETEYRCDDSKTDISWLREP- } 957\end{array}$

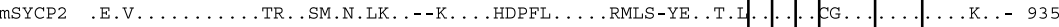

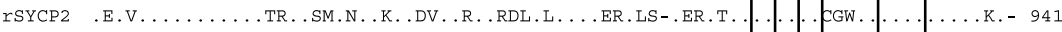

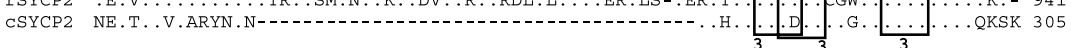

hSYCP2 -KSKPQLIDYSRNKNVKNHKSGK----SRSSLEKGQPSSKMTPSKNITKKMDKTIPEGRIRLPRKATKTKKNYKDLSN- - 1030

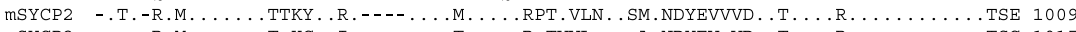

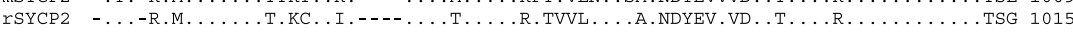
CSYCP2 AP.... I. . . . . . . LGKSNRKGKNEF. DPPCQMDA. KG. RAKK. KP. ECKKQSSVIDE. MEQSTRP. RPQRAVQPK. YK 385

hSYCP2 SESECEREFSHSFKENI PVKEENIHSRMKTVKLPKKQQKVFCAETEK-ELSKQWKNSSLLKDAIRDNCLDISARSLSGSP 1109

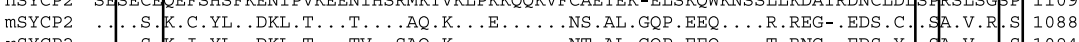

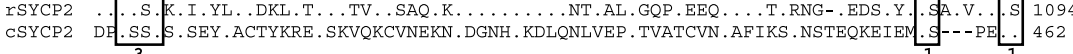

hSYCP2 SSIEVTRCIEKITEKDFTQDYDCITKS-_-_._-_-ISPYPKTSSLE---SLNSNSGVGGTIKSPKNNEKNFLCASE 1174

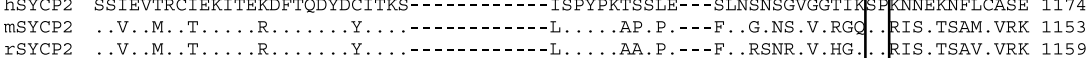

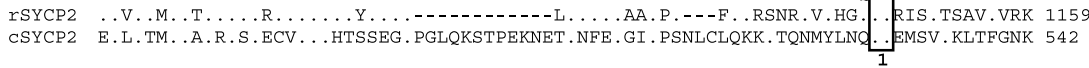

hSYCP2 SOSPIPRPLFLPRHPPTKSNTIVNRKKISSLVLTQETQNSNSYSDVSSYSSEERFMEIESPHINENYIQSKREESHLA SS 1254

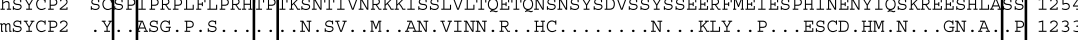

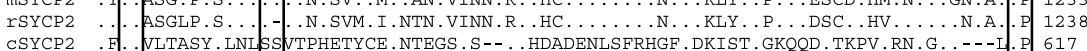
hSYCP2 LSKSSEGREKTWFDMPCDATHVSGPTQHLSRKRIYIEDN-LSNSNEVEMEEKGERRANLLPKKLCKIEDADHHIHKMSES 1333

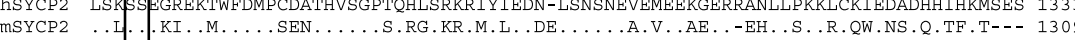

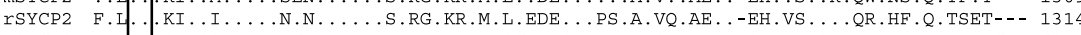
CSYCP2 V.I. SEVQS. NQE . .GP . E . . . . S.VFL . K. QC.TESHSDEVETSK. EEKK. SRRTKLQPR. LFKT.EAVTYRG-- 695

hSYCP2 VSSISTNDFSIPWETWQNEFAGIEMTYETYERLNSEFKRRNNIRHKMLSYFTT OSWK PAQQHLRTMNHQSQDSRIKKLDK 1413 mSYCP2 - . . P...V.-KD .Q.LQ.AG.F.DN- - IS.DY . KTDSQ. IMDD . . . KTL.ET. . . MA.TS.A.GR.DENVE. 1383

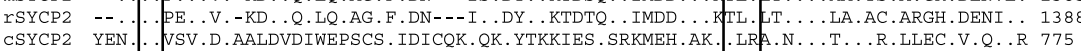
CSYCP2 YEN. . . VSV.D.AALDVDIWEPSCS. IDICQK.QK.YTKKIES.SRKMEH.AK. $\frac{1}{2}$. LRA.N . . T . . R. LLEC.V.Q. R 775

hSYCP2 FQFIIIEELENFEKDSQSLKDLEKEFVDFWEKIFQKFSAYQKSEQQRLHLLKTSLAKSVFCN-TDSEETVFTSEMCLMKE 1492

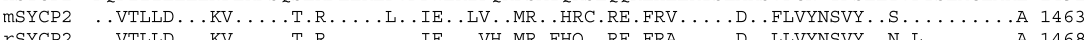

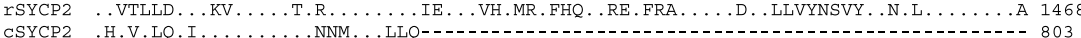

hSYCP2 DMKVLQDRLLKDMLEEELLNVRRELMSVFMSHERNANV 1530

mSYCP2 N..M..K...E.H..V..I.G.Q.L.KA..G.DA- 1500

$\begin{array}{lll}\text { MSYCP2 } & \text { N..M...K...E.H...V..I.G.Q.L.KA..G.DA- } 1500 \\ \text { YSYCP2 } & \text { N..M...K..E.H.....I..G.E.L.KD..G.NA- } 1505\end{array}$

$\begin{array}{lll}\text { ISYCP2 } & \text { N..M...K...E.H.........G.E.L.KD..G.NA- } 1505 \\ \text { CSYCP2 } & -\ldots . \ldots \text {............G.QTL.LAEDGKF-- } 825\end{array}$

Reproduction (2009) 138 483-492
Figure 2 Amino acid sequence alignment of synaptonemal complex protein 2 (SYCP2) proteins. Amino acid sequences of known SYCP2 proteins from humans (hSYCP2), mice (mSYCP2) and rats ( $\mathrm{rSYCP} 2)$ were compared with the predicted SYCP2 protein from chickens (cSYCP2) using the CLUSTAL X programme and edited with the BioEdit programme. Dots indicate amino acids identical to hSYCP2 and dashes represent gaps in the sequence. Amino acid sequences shown in boxes are the following: 1) DNAbinding sites (S/T-P motifs and S/T-S/T motifs), 2) protein kinase $C$ phosphorylation sites (S/T-X-R/K), 3) casein kinase II phosphorylation sites (S/T-X-X-D/E), and 4) GTP-binding sites (D-X-X-G), which are conserved in both hSYCP2 and $\mathrm{CSYCP} 2$. 


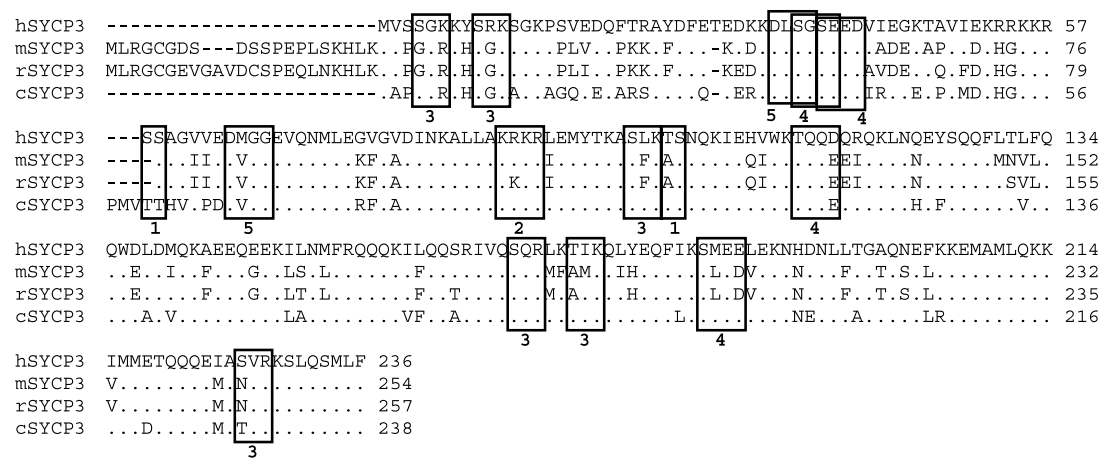

Figure 3 Amino acid sequence alignment of synaptonemal complex protein 3 (SYCP3) proteins. Amino acid sequences of known SYCP3 proteins from humans (hSYCP3), mice (mSYCP3) and rats ( $\mathrm{rSYCP} 3$ ) were compared with the predicted SYCP3 protein from chickens (cSYCP3) using the CLUSTAL X programme and edited with the BioEdit programme. Dots indicate amino acids identical to hSYCP3 and dashes represent gaps in the sequence. Amino acid sequences shown in boxes are the following: 1) DNA-binding sites (S/T-S/T motifs), 2) nuclear localisation signal $(\mathrm{K}-\mathrm{R} / \mathrm{K}-\mathrm{X}-\mathrm{R} / \mathrm{K}$, where $\mathrm{X}$ represents any amino acid), 3) protein kinase $\mathrm{C}$ phosphorylation sites (S/T-X-R/K), 4) casein kinase II phosphorylation sites (S/T-X-X-D/E), and 5) GTP-binding sites (D-X-X-G), which are conserved in both hSYCP3 and cSYCP3.

\section{Discussion}

BLAST searches of eukaryotic genomes revealed that in many non-mammalian species, all three SYCP family members had not been completely characterised. In this paper, we focused on investigating the chicken homologues of SYCP family members, CSYCP1, CSYCP2 and CSYCP3. To understand the functional similarities and/or dissimilarities, one must characterise the structural features of cSYCP family members and analyse their conservation with mammalian homologues. The predicted amino acid sequences of cSYCP family proteins share several potential functional sites including nuclear localisation signals (K-R/K-X-R/K), PKC phosphorylation sites $(S / T-X-R / K)$, casein kinase II phosphorylation sites (S/T-X-X-D/E) and S/T-P or S/T-S/T motifs for DNA binding that may play a role in assembly and disassembly of SCs. However, a few significant differences in structural features exist between the CSYCP family proteins. For example, both cSYCP1 and cSYCP2 contain one or more potential cAMP/cGMP-dependent protein kinase target sites (RR/KK-X-S/T): these are found at amino acids 362-365 in CSYCP1 and at amino acids 39-42, 350-353, 356-359, 518-521, 535-538 and 671-674 in CSYCP2. However, cSYCP3 does not contain any CAMP/CGMP-dependent protein kinase phosphorylation sites. CAMP/cGMP-dependent protein kinase is important for regulating the assembly and disassembly of the LEs, and inhibition of this phosphorylation site leads to the disassembly of the nuclear lamina (Lammers et al. 1994). Of the three cSYCP family members, only CSYCP2 contained a potential tyrosine kinase phosphorylation site with the consensus R/K-X-X-D/E-X-X-X-Y; this site was found at amino acids 686-693. The primary amino acid sequences of tyrosine kinases are closely related to serine- and threonine-specific kinases such as cAMP-dependent protein kinase, PKC and phosphorylase kinase (Akiyama et al. 1987). Inhibition of tyrosine kinases produces meiosis I arrest by inducing rapid dissolution of SCs and bivalent separation (Tarsounas et al. 1999).

The differences in structural features between the CSYCP family proteins suggest that CSYCP1, CSYCP2 and CSYCP3 may vary in one or more functions during the assembly and disassembly of SCs even though these genes are from same family. Among the structural features identified, several DNA-binding sequences, nuclear localisation signals, PKC phosphorylation sites, casein kinase II phosphorylation sites and GTP-binding sequences of CSYCP family proteins are highly conserved with hSYCP family proteins, which indicates that the two families may have close functional relationships.

In mammals, SYCP family genes are not expressed in any tissues other than testis and ovary (Wang et al. 2001). During embryogenesis, all SYCP family members are expressed specifically in the nucleus of meiotic prophase I cells (spermatocytes in males and oocytes in females). SYCP3 appears first at the leptotene stage, and subsequently SYCP1 and SYCP2 appear at the zygotene and pachytene stages respectively (Meuwissen et al. 1992, Lammers et al. 1994, Offenberg et al. 1998, Yuan et al. 2000), but pre-meiotic cells (spermatogonia in males and oogonia in females) do not contain detectable amounts of SYCP mRNA. After sexual maturation, expression of mammalian $S Y C P$ family members is specific to testis and restricted to meiotic prophase I spermatocytes (Offenberg et al. 1998, Yang et al. 2006). Interestingly, recent reports demonstrate the expression of mammalian SYCP family members in adult human ovaries (Bukovsky et al. 2008) and show that transplanted female germline stem cells derived from adult mouse ovaries underwent oogenesis and the mice produced offspring (Zou et al. 2009). To our knowledge, less is known about tissue- and cell-specific expression of SYCP family members in chickens. In the present study, qRT-PCR analysis revealed that the three members 

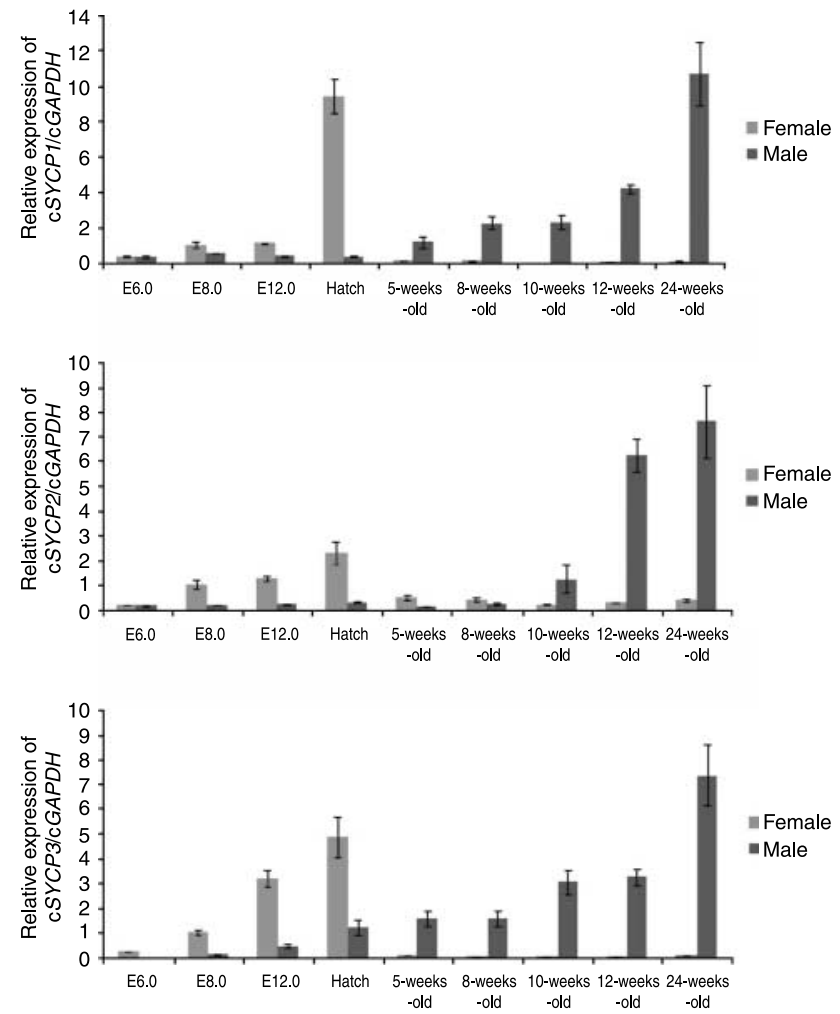

Figure 4 Quantitative real-time-PCR analysis of chicken homologues of synaptonemal complex protein (CSYCP) family members during ovarian and testicular development. The threshold cycle $\left(C_{\mathrm{t}}\right)$ of each gene was normalised to an endogenous housekeeping gene, chicken glyceraldehyde-3-phosphate dehydrogenase (cGAPDH). Relative quantification of gene expression was calculated using the $2^{-\Delta \Delta C_{t}}$ method. Values on the $y$-axis show the relative expression of gene/GAPDH. Each bar represents the mean \pm s.E.M. of three independent experiments.

of the ${ } S Y C P$ family were differentially expressed in a tissue-specific and duration-dependent manner. cSYCP1 and $\mathrm{CSYCP} 2$ were initially expressed on E6.0 in both testis and ovary, whereas $\mathrm{C} S Y C P 3$ was initially expressed on E6.0 in females and on E8.0 in males. The onset of meiosis in chickens occurs first in female gonads on E15.5 (Smith et al. 2008). The duration-dependent expression of cSYCP family members in the present study calls into question the idea that cSYCP family members are specific to meiotic prophase I or are initially expressed only after pre-meiotic development of germ cells.

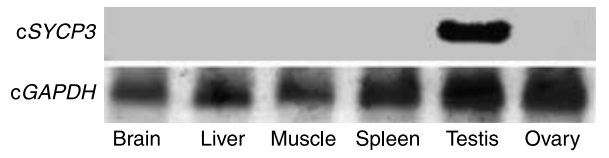

Figure 5 Northern blot analysis of chicken synaptonemal complex protein 3 (CSYCP3) in the brain, liver, muscle, spleen, testis and ovary in 24-week-old chickens. The same RNA samples were hybridised with probes made from the endogenous housekeeping gene, chicken glyceraldehyde-3-phosphate dehydrogenase (cGAPDH) for normalisation.

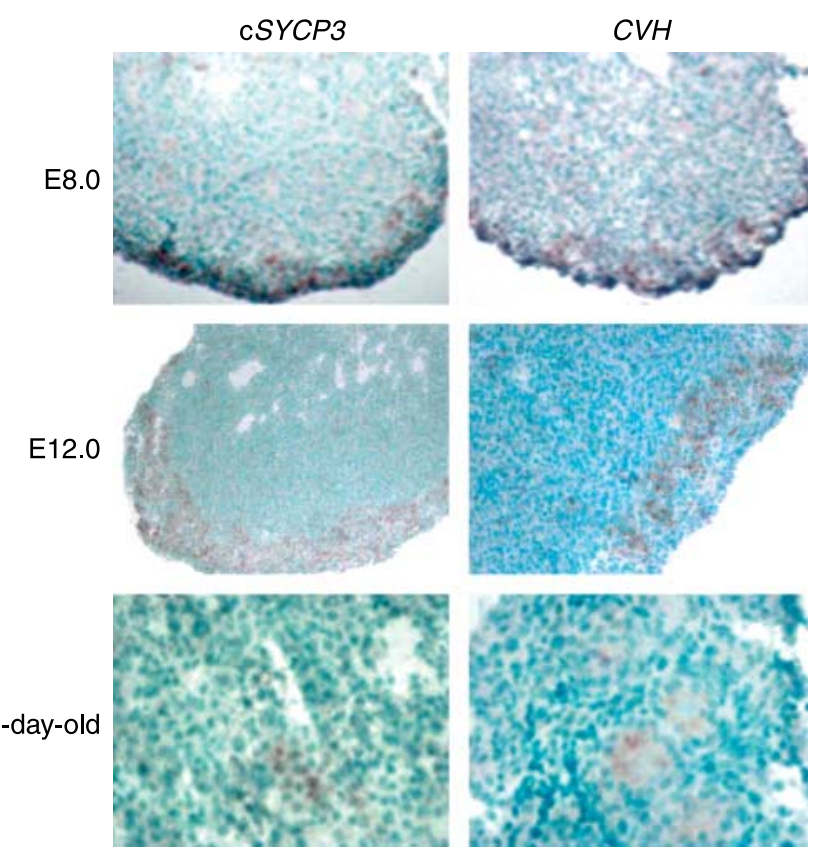

Figure 6 mRNA localisation of chicken synaptonemal complex protein 3 (cSYCP3) during ovarian development on E8.0, E12.0 and 1 day compared with a germline-specific gene chicken vasa homologue $(C V H)$ as a positive control. Original magnification, $\times 200$.

We examined the relationship between the expression pattern of cSYCP family members and the time- and duration-dependent events of gametogenesis to identify the stage at which these genes act during germline development and onset of meiosis (Fig. 8). In chickens, the germ cell lineage is maternally predetermined from the first cleavage of the fertilised egg, but most studies have traced germline development from $\mathrm{H} \& \mathrm{H}$ stage $X$ (E0.0, the freshly laid egg; Hamburger \& Hamilton 1951, Ginsburg \& Eyal-Giladi 1986, Tsunekawa et al. 2000). The precursors of germ cells, PGCs, appearing in the area pellucida at stage $X$ will eventually migrate to the germinal crescent area during formation of the primitive streak on E0.5 (Tsunekawa et al. 2000). At around E2.0 to E4.0, PGCs circulate in the extraembryonic blood stream (Yamamoto et al. 2007). Although PGCs enter germinal ridges on about E4.0, differentiation of PGCs into oogonia in females and pro-spermatogonia in males starts on about E8.0 and E13.0 respectively (Aramaki et al. 2007, Nakamura et al. 2007). In the present study, qRT-PCR and in situ hybridisation results revealed that the earliest expression of $\mathrm{C} S Y C P$ family members began in chicken PGCs, which settle in the differentiating gonads on E6.0 (Aramaki et al. 2007). In mammals, expression of SYCP members was reported in PGCs before meiotic arrest (Di Carlo et al. 2000).

In female chickens, the oogonia enter a dramatic proliferation state on E9.0; however, entry of oogonia into meiosis and arrest at prophase I were clearly seen as early as day E15.5. After E16.5, meiotic oocytes were 


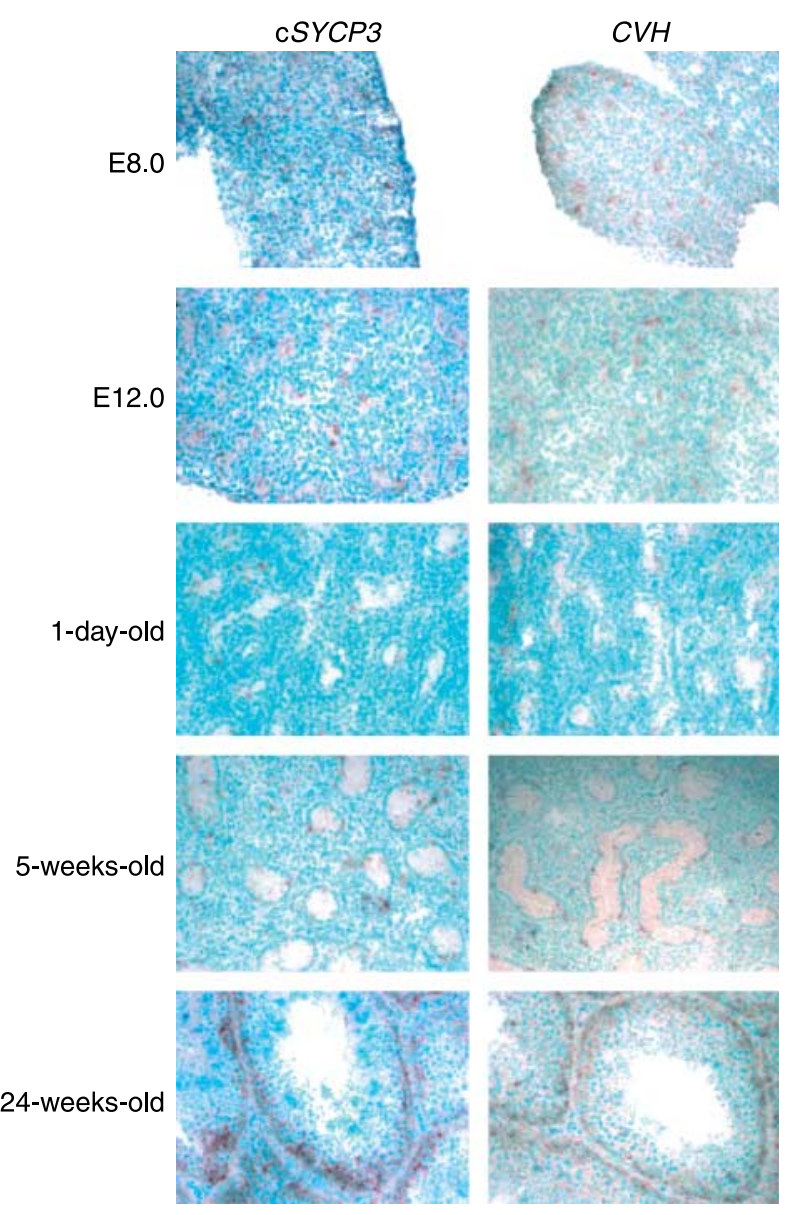

Figure 7 mRNA localisation of chicken synaptonemal complex protein 3 (cSYCP3) during testicular development on E8.0, E12.0, 1 day, 5 weeks and 24 weeks compared with the germline-specific gene, chicken vasa homologue $(\mathrm{CVH})$ as a positive control. Original magnification, $\times 200$.

numerous in the female gonad (Hughes 1963, Smith et al. 2008). In male chickens, PGCs undergo mitotic arrest: they stop dividing and remain as pro-spermatogonia at the G1 stage of the cell cycle until hatching (Kirby \& Froman 2000, Smith et al. 2008). After hatching, both spermatogonia and Sertoli cells undergo proliferation until about 8 weeks of age. Spermatogonia enter meiosis only after the completion of Sertoli cell proliferation. Therefore, the majority of cell types present in the seminiferous tubules up to 8 weeks are spermatogonia and Sertoli cells (Kirby \& Froman 2000). We believe that in females, all CSYCP family members first appeared in PGCs on E6.0 and that the mRNA level increased sharply at the onset of meiosis. In males, however, cSYCP family members first appeared in the PGCs, expression continued in pro-spermatogonia and proliferating spermatogonia and expression increased when the germ cells entered meiosis. Ovarian expression of cSYCP family members in adult chickens may be indicative of ongoing oogenesis.
Not surprisingly, the ovarian expression is much lower compared with testis, just reflecting decline of oocyte numbers after hatching.

In conclusion, we investigated the expression pattern of chicken homologues of meiosis-associated SYCP family members, which were highly conserved with mammalian SYCP family proteins. The expression pattern of all cSYCP family members was identified in both ovary and testis; however, the mRNAs expression was much lower in testis during embryonic stages and much lower in ovary during post-hatch development. All cSYCP family members were initially expressed in PGCs and continued to be expressed in premeiotic germ cells, and the expression level increased when the germ cells entered meiosis.

\section{Materials and Methods Animals}

White Leghorn chickens were maintained at the University Animal Farm, Seoul National University. Animal management, reproduction and surgery were performed in accordance with standard protocols of the Division of Animal Genetic Engineering, Seoul National University. All experimental data reported in the present study were from at least three independent experiments.

\section{Tissues, total RNA extraction and CDNA synthesis}

In total, 30 tissues were collected during the sexual development of male and female chickens: male and female gonads on E6.0, 8.0 and 12.0; testis and ovary at 1 day (hatching), 1, 2, 3, 4, 5, 8, 10, 12 and 24 weeks; and brain, liver, muscle and spleen at 24 weeks. Sex was determined on E4.0 by PCR using W chromosome-specific primers (USP1: 5'-CTATGCCTACCACATTCCTATTTGC and USP3: 5'-AGCTGGACTTCAGACCATCTTCT; Ogawa et al. 1997). Total RNA was extracted using Trizol reagent (Invitrogen) according to the manufacturer's protocol. About $0.5 \mu \mathrm{g}$ total RNA was reversetranscribed with the Superscript III First-Strand Synthesis System (Invitrogen) according to the manufacturer's protocol.

\section{Multiple sequence alignment of SYCP family members}

Predicted cSYCP1, cSYCP2 and $\mathrm{c} S Y C P 3$ mRNA sequences were obtained from the BLAT search of the Chicken Genome Database at the University of California, Santa Cruz (UCSC; Karolchik et al. 2008) for the respective GenBank sequences (cSYCP1:XM_001235268, cSYCP2; XM_417396 and cSYCP3: XM_416330) from the National Centre for Biotechnology Information (NCBI; Benson et al. 2004). Amino acid sequences of cSYCP1, cSYCP2 and cSYCP3 proteins (XP_001235269, $X P \_417396$ and $X P \_416330$ respectively) were compared to the SYCP family proteins of humans (NP_003167, NP_055073 and NP_710161 respectively), mice (NP_035646, NP_796165 and NP_035647 respectively) and rats (NP_036942, NP_570091 and NP_037173 respectively) using the CLUSTAL 

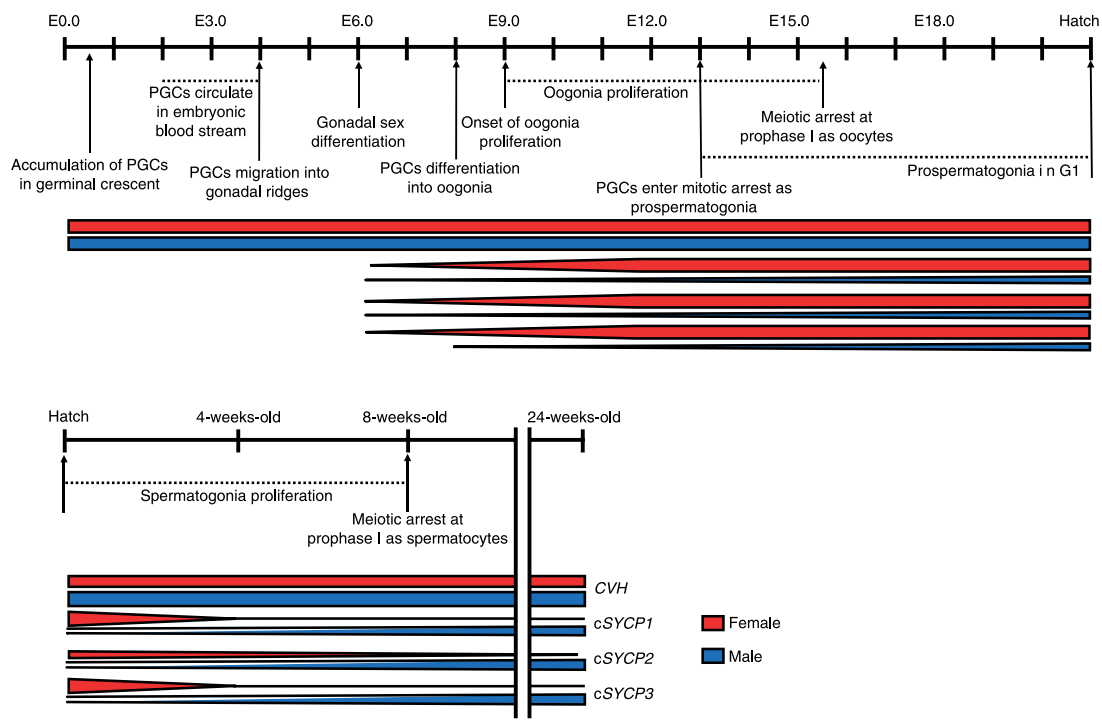

Figure 8 Schematic representation of the expression pattern of chicken homologues of synaptonemal complex proteins (cSYCP1, cSYCP2 and $\mathrm{CSYCP3)}$ and the germline-specific gene, chicken vasa homologue $(\mathrm{CVH})$ compared with time- and duration-dependent events of germline development until the onset of meiosis.
$X$ programme and edited with the BioEdit programme (Lee et al. 2008). The percent identity between SYCP proteins of chickens, humans, mice and rats was determined using the NCBI blastp engine (Tatusova \& Madden 1999).

\section{qRT-PCR}

To examine the expression pattern of cSYCP1, cSYCP2 and cSYCP3 during ovarian and testicular development, qRT-PCR was performed in an iCycler real-time PCR detection system (Bio-Rad Laboratories). The PCR reaction mixture contained $2 \mu \mathrm{l}$ PCR buffer, $1.6 \mu \mathrm{l}$ of $2.5 \mathrm{mM}$ dNTP mixture, $10 \mathrm{pmol}$ each of forward and reverse primers (Table 1), $2 \mu \mathrm{l} \mathrm{cDNA,} 1 \mu$ l EvaGreen (Biotium Inc., Hayward, CA, USA) and 1 U Taq DNA polymerase in a $20 \mu \mathrm{l}$ final volume. PCR was performed with initial incubation at $50{ }^{\circ} \mathrm{C}$ for $2 \mathrm{~min}$ and $95^{\circ} \mathrm{C}$ for $10 \mathrm{~min}$, followed by 40 cycles at $95{ }^{\circ} \mathrm{C}$ for $15 \mathrm{~s}, 58^{\circ} \mathrm{C}$ for $30 \mathrm{~s}$ and $72{ }^{\circ} \mathrm{C}$ for $30 \mathrm{~s}$. PCR was terminated by a final incubation at the dissociation temperatures of $95{ }^{\circ} \mathrm{C}$ for $15 \mathrm{~s}, 60{ }^{\circ} \mathrm{C}$ for $30 \mathrm{~s}$ and $95^{\circ} \mathrm{C}$ for $15 \mathrm{~s}$. The threshold cycles $\left(C_{\mathrm{t}}\right)$ of cSYCP1, cSYCP2 and $C S Y C P 3$ were normalised with chicken glyceraldehyde-3phosphate dehydrogenase (cGAPDH, primers shown in Table 1). Relative quantification of the expression of genes was calculated using the $2^{-\Delta \Delta C_{\mathrm{t}}}$ method (Livak \& Schmittgen 2001).

\section{Hybridisation probes}

Testis cDNA from 24-week-old chickens was amplified with cSYCP3-, cGAPDH- and $\mathrm{CVH}$-specific primers (Table 1). The amplified fragments were separated by gel electrophoresis and extracted with a Power Gel Extraction kit (TaKaRa Korea Biomedical Inc., Seoul, South Korea) and cloned into the pGEM-T Easy vector (Promega). After linearisation of sequences, recombinant plasmids containing each gene were

Table 1 Primers used for $\mathrm{CSYCP}$ family members, $\mathrm{CGAPDH}$ and $C V H$ examined by quantitative real-time-PCR, northern hybridisation and in situ hybridisation in chickens.

\begin{tabular}{|c|c|c|c|}
\hline Gene & Accession no. & Primer sequences & Size (bp) \\
\hline \multirow[t]{2}{*}{ сSYCP1 } & XM_001235268 & F: 5'-GCAGTCAAACCCCAGACCA & 100 \\
\hline & & R: 5'-TCTTCTCAGССТССТTGTAGAGTT & \\
\hline \multirow[t]{2}{*}{$\mathrm{C} S Y C P 2$} & XM_417396 & F: 5'-GCTGGCTACAAAAATCCAAAG & 97 \\
\hline & & R: 5'-GGCAAGGAGGGTCAGAGAAC & \\
\hline \multirow[t]{4}{*}{$\mathrm{CSYCP3^{ \textrm {a } }}$} & XM_416330 & F: 5'-TACAAAAGCCTCACTCAAAACC & 140 \\
\hline & & R: 5'-TTTCCTCCTGTTCCTCTGCT & \\
\hline & & F: 5'-GACAGGAAGAGCAAGCCAG & 401 \\
\hline & & R: 5'-СТССТGTТССТСТGСТTТСТG & \\
\hline \multirow[t]{4}{*}{$\mathrm{cGAPDH} H^{\mathrm{a}}$} & NM_204305 & F: 5'-CCGTGTTGTGGACTTGATGG & 156 \\
\hline & & R: 5'-GAGGAGTGGGGGAGACAGAA & \\
\hline & & F: 5'-CACAGCCACACAGAAGACGG & 443 \\
\hline & & R: 5'-CCATCAAGTCCACAACACGG & \\
\hline \multirow[t]{2}{*}{$\mathrm{CVH}$} & NM_204708 & F: 5'-GGGAAGATCAGTTTGGTGGA & 388 \\
\hline & & R: 5'-GACAAAGAAAGGCTGCAAGG & \\
\hline
\end{tabular}

cSYCP1, chicken synaptonemal complex protein 1; cSYCP2, chicken synaptonemal complex protein 2; cSYCP3, chicken synaptonemal complex protein 3; cGAPDH, chicken glyceraldehydes-3-phosphate dehydrogenase; $\mathrm{CVH}$, chicken vasa homolog.

${ }^{a}$ First primer pairs were used for qRT-PCR, and second primer pairs were used for the synthesis of hybridisation probes. 
amplified with T7- and SP6-specific primers (T7: 5'-TGTAATACGACTCACTATAGGG; SP6: 5'-CTATTTAGGTGACACTATAGAAT). The recombinant DNA was labelled with a digoxigenin (DIG) RNA labelling kit (Roche Diagnostics) to prepare sense and antisense cRNA probes for hybridisation.

\section{Northern hybridisation}

Tissue-specific expression of $\mathrm{CSYCP} 3$ was confirmed by northern blotting using a DIG Northern Starter Kit (Roche; Holtke et al. 1995). Total RNAs from the brain, liver, muscle, spleen, testis and ovary of 24-week-old chickens were electrophoresed in a $1 \%(\mathrm{w} / \mathrm{v})$ formaldehyde agarose gel, capillary-blotted onto Hybond nylon membrane (Amersham Biosciences) and u.v. cross-linked. Blots were hybridised with cSYCP3 and cGAPDH probes. After non-specific binding was blocked by incubating the membrane in $1 \%(\mathrm{w} / \mathrm{v})$ blocking reagent (Roche), the membrane was incubated with anti-DIG antibody (Roche) for $1 \mathrm{~h}$ at room temperature. The signal was developed with nitroblue tetrazolium (NBT) and 5-bromo-4chloro-3-indolyl phosphate (BCIP; Sigma-Aldrich) for $5 \mathrm{~h}$ in the dark.

\section{In situ hybridisation}

In situ hybridisation was performed to examine the mRNA localisation of cSYCP3 during ovarian and testicular development in comparison to $\mathrm{CVH}$. Frozen sections $(10 \mu \mathrm{m})$ were mounted on slides treated with 3-aminopropyltriethoxysilane (Sigma-Aldrich). The sections were dried on a $50{ }^{\circ} \mathrm{C}$ slide warmer and fixed in $4 \%(\mathrm{w} / \mathrm{v})$ paraformaldehyde in PBS $(\mathrm{pH} 7.4)$ for $1 \mathrm{~h}$ at room temperature. The sections were washed twice in PBS, treated in 1\% (v/v) Triton-X-100 for $20 \mathrm{~min}$ and washed three times in PBS. The sections were incubated with a prehybridisation mixture containing 50\% (w/v) formamide and 5 $\times$ SSC $(\mathrm{pH} \mathrm{7.0)}$ for $15 \mathrm{~min}$ at room temperature. After pre-hybridisation, the sections were hybridised with sense or antisense $\mathrm{c} S Y C P 3$ and $C V H$ cRNA probes in a hybridisation solution for $18 \mathrm{~h}$ at $55^{\circ} \mathrm{C}$ (Rengaraj et al. 2008). After the sections were incubated overnight with sheep anti-DIG antibody (Roche), the mRNA signal was visualised with NBT and BCIP. The sections were counterstained with $1 \%(\mathrm{w} / \mathrm{v})$ methyl green (Sigma-Aldrich) and photographs were taken under an Axiophot light microscope (Carl Zeiss, Oberkochen, Germany).

\section{Declaration of interest}

The authors declare that there is no conflict of interest that could be perceived as prejudicing the impartiality of the research reported.

\section{Funding}

This work was supported by a grant from the BioGreen 21 Programme, RDA, a graduate fellowship from the Brain Korea 21 Programme and World Class University Programme (R31-2008-000-10056-0) of the Ministry of Education, Science and Technology, Korea.

\section{References}

Akiyama T, Ishida J, Nakagawa S, Ogawara H, Watanabe S, Itoh N, Shibuya M \& Fukami Y 1987 Genistein, a specific inhibitor of tyrosine-specific protein kinases. Journal of Biological Chemistry 262 5592-5595.

Aramaki S, Sato F, Kato T, Soh T, Kato Y \& Hattori MA 2007 Molecular cloning and expression of dead end homologue in chicken primordial germ cells. Cell and Tissue Research 330 45-52.

Benson DA, Karsch-Mizrachi I, Lipman DJ, Ostell J \& Wheeler DL 2004 GenBank: update. Nucleic Acids Research 32 D23-D26.

Bukovsky A, Caudle MR, Gupta SK, Svetlikova M, Selleck-White R, Ayala AM \& Dominguez R 2008 Mammalian neo-oogenesis and expression of meiosis-specific protein SCP3 in adult human and monkey ovaries. Cell Cycle 7 683-686.

Cooper JA, Esch FS, Taylor SS \& Hunter T 1984 Phosphorylation sites in enolase and lactate dehydrogenase utilized by tyrosine protein kinases in vivo and in vitro. Journal of Biological Chemistry 259 7835-7841.

Costa Y, Speed R, Ollinger R, Alsheimer M, Semple CA, Gautier P, Maratou K, Novak I, Hoog C, Benavente R et al. 2005 Two novel proteins recruited by synaptonemal complex protein 1 (SYCP1) are at the centre of meiosis. Journal of Cell Science 118 2755-2762.

Dever TE, Glynias MJ \& Merrick WC 1987 GTP-binding domain: three consensus sequence elements with distinct spacing. PNAS $\mathbf{8 4}$ 1814-1818.

Di Carlo AD, Travia G \& De Felici M 2000 The meiotic specific synaptonemal complex protein SCP3 is expressed by female and male primordial germ cells of the mouse embryo. International Journal of Developmental Biology 44 241-244.

Ginsburg M \& Eyal-Giladi H 1986 Temporal and spatial aspects of the gradual migration of primordial germ cells from the epiblast into the germinal crescent in the avian embryo. Journal of Embryology and Experimental Morphology 95 53-71.

Glass DB, el-Maghrabi MR \& Pilkis SJ 1986 Synthetic peptides corresponding to the site phosphorylated in 6-phosphofructo-2-kinase/ fructose-2,6-bisphosphatase as substrates of cyclic nucleotide-dependent protein kinases. Journal of Biological Chemistry 261 2987-2993.

Hamburger V \& Hamilton HL 1951 A series of normal stages in the development of the chick embryo. Journal of Morphology 88 49-92.

Holtke HJ, Ankenbauer W, Muhlegger K, Rein R, Sagner G, Seibl R \& Walter T 1995 The digoxigenin (DIG) system for non-radioactive labelling and detection of nucleic acids - an overview. Cellular and Molecular Biology 41 883-905.

Hughes GC 1963 The population of germ cells in the developing female chick. Journal of Embryology and Experimental Morphology 11 513-536.

Karolchik D, Kuhn RM, Baertsch R, Barber GP, Clawson H, Diekhans M, Giardine B, Harte RA, Hinrichs AS, Hsu F et al. 2008 The UCSC genome browser database: 2008 update. Nucleic Acids Research $\mathbf{3 6}$ D773-D779.

Kirby JD \& Froman DP 2000 Reproduction in male birds. In Avian Physiology, 5 edn, pp 597-615. Ed. GC Whittow. San Diego: Academic Press.

Kishimoto A, Nishiyama K, Nakanishi H, Uratsuji Y, Nomura H, Takeyama Y \& Nishizuka Y 1985 Studies on the phosphorylation of myelin basic protein by protein kinase $C$ and adenosine $3^{\prime}, 5^{\prime}$ monophosphate-dependent protein kinase. Journal of Biological Chemistry 260 12492-12499.

Lammers JH, Offenberg $\mathbf{H H}$, van Aalderen M, Vink AC, Dietrich AJ \& Heyting C 1994 The gene encoding a major component of the lateral elements of synaptonemal complexes of the rat is related to X-linked lymphocyte-regulated genes. Molecular and Cellular Biology 14 1137-1146.

Lee JY, Lim JM, Kim DK, Zheng YH, Moon S, Han BK, Song KD, Kim H \& Han JY 2008 Identification and gene expression profiling of the Pum1 and Pum2 members of the Pumilio family in the chicken. Molecular Reproduction and Development 75 184-190.

Livak KJ \& Schmittgen TD 2001 Analysis of relative gene expression data using real-time quantitative PCR and the $2(-$ Delta Delta $C(T))$ method. Methods 25 402-408. 
Meuwissen RL, Offenberg HH, Dietrich AJ, Riesewijk A, van lersel M \& Heyting C 1992 A coiled-coil related protein specific for synapsed regions of meiotic prophase chromosomes. EMBO Journal 11 5091-5100.

Meuwissen RL, Meerts I, Hoovers JM, Leschot NJ \& Heyting C 1997 Human synaptonemal complex protein 1 (SCP1): isolation and characterization of the cDNA and chromosomal localization of the gene. Genomics 39 377-384.

Nakamura Y, Yamamoto Y, Usui F, Mushika T, Ono T, Setioko AR, Takeda K, Nirasawa K, Kagami H \& Tagami T 2007 Migration and proliferation of primordial germ cells in the early chicken embryo. Poultry Science $\mathbf{8 6}$ 2182-2193.

Offenberg HH, Schalk JA, Meuwissen RL, van Aalderen M, Kester HA, Dietrich AJ \& Heyting C 1998 SCP2: a major protein component of the axial elements of synaptonemal complexes of the rat. Nucleic Acids Research 26 2572-2579.

Ogawa A, Solovei I, Hutchison N, Saitoh Y, Ikeda JE, Macgregor H \& Mizuno S 1997 Molecular characterization and cytological mapping of a non-repetitive DNA sequence region from the $W$ chromosome of chicken and its use as a universal probe for sexing Carinatae birds. Chromosome Research 5 93-101.

Ollinger R, Alsheimer M \& Benavente R 2005 Mammalian protein SCP1 forms synaptonemal complex-like structures in the absence of meiotic chromosomes. Molecular Biology of the Cell 16 212-217.

Pinna LA 1990 Casein kinase 2: an 'eminence grise' in cellular regulation? Biochimica et Biophysica Acta 1054 267-284.

Rengaraj D, Kim DK, Zheng YH, Lee SI, Kim H \& Han JY 2008 Testisspecific novel transcripts in chicken: in situ localization and expression pattern profiling during sexual development. Biology of Reproduction 79 413-420.

Roberts B 1989 Nuclear location signal-mediated protein transport. Biochimica et Biophysica Acta 1008 263-280.

Smith CA, Roeszler KN, Bowles J, Koopman P \& Sinclair AH 2008 Onset of meiosis in the chicken embryo: evidence of a role for retinoic acid. BMC Developmental Biology 885.
Suzuki M 1989 SPXX, a frequent sequence motif in gene regulatory proteins. Journal of Molecular Biology 207 61-84.

Tarsounas M, Pearlman RE \& Moens PB 1999 Meiotic activation of rat pachytene spermatocytes with okadaic acid: the behaviour of synaptonemal complex components SYN1/SCP1 and COR1/SCP3. Journal of Cell Science 112 423-434.

Tatusova TA \& Madden TL 1999 BLAST2 sequences, a new tool for comparing protein and nucleotide sequences. FEMS Microbiology Letters 174 247-250.

Tsunekawa N, Naito M, Sakai Y, Nishida T \& Noce T 2000 Isolation of chicken vasa homolog gene and tracing the origin of primordial germ cells. Development 127 2741-2750.

Wang PJ, McCarrey JR, Yang F \& Page DC 2001 An abundance of X-linked genes expressed in spermatogonia. Nature Genetics 27 422-426.

Yamamoto $Y$, Usui F, Nakamura $Y$, Ito $Y$, Tagami T, Nirasawa K, Matsubara Y, Ono T \& Kagami H 2007 A novel method to isolate primordial germ cells and its use for the generation of germline chimeras in chicken. Biology of Reproduction 77 115-119.

Yang F, De La Fuente R, Leu NA, Baumann C, McLaughlin KJ \& Wang PJ 2006 Mouse SYCP2 is required for synaptonemal complex assembly and chromosomal synapsis during male meiosis. Journal of Cell Biology 173 497-507.

Yuan L, Liu JG, Zhao J, Brundell E, Daneholt B \& Hoog C 2000 The murine SCP3 gene is required for synaptonemal complex assembly, chromosome synapsis, and male fertility. Molecular Cell 5 73-83.

Zou K, Yuan Z, Yang Z, Luo H, Sun K, Zhou L, Xiang J, Shi L, Yu Q, Zhang Y et al. 2009 Production of offspring from a germline stem cell line derived from neonatal ovaries. Nature Cell Biology 11 631-636.

Received 24 April 2009

First decision 13 May 2009

Revised manuscript received 6 June 2009

Accepted 12 June 2009 